\title{
THE RISK OF POST PARTUM HEMORRHAGE AFTER CESAREAN SECTION WITH GENERAL VERSUS SPINAL/EPIDURAL ANAESTHESIA
}

\author{
Tarek M.A. El-Beheidy; Amal A.E. Nouh; \\ Ahmed M.A. Abo Elmaaty* and Hanaa H. Abdel Hafeiz \\ Obstetrics and Gynecology and Anaesthesia and Surgical Intensive Care* Departments, \\ Faculty of Medicine, Zagazig University
}

\begin{abstract}
Background: In this study, we set out to compare the risk of PPH after CS for those who receive general versus spinal/epidural anesthesia with the use of a one-year dataset, we hypothesized that women who received general anesthesia would be at higher risk of PPH compared with women who received epidural anesthesia because adverse uterine contraction and platelet function might be associated with general anesthesia.. Objectives: To assess frequency of postpartum hemorrhage in general anaesthesia, to assess frequency of postpartum hemorrhage in spinal anaesthesia, to compare the risk of Postpartum Hemorrhage (PPH) for patients who will undergo CS with general versus spinal/epidural anesthesia and to assess risk of type of anaesthesia in developing PPH. Patients and methods: This is a retrospective study on patients complicted by PPH after CS with history of type of anaesthesia used; general or spinal/epidural anaesthesia to detect the risk of developing PPH. We included all women complicated by PPH after CS and collect data about the anaesthesia used during CS and other risk factors for PPH if recorded in files of operative sheet of the patients. Hemoglobin concentration before surgery and on first postoperative day was recorded for all patients. The total volume of crystalloid solutions infused during operation and duration of operation were determined. Results: Our results showed that $42.3 \%$ of the studied group had general anaesthesia and $57.7 \%$ of them had spinal anaesthesia. There was statistical significant difference between patients who received general anesthesia and patients who received spinal anaesthesia in number of cases having postpartum hemorrhage.. Conclusion: The odds that women will experience caesarean PPH with general anaesthesia are approximately 3.5times higher than for women who undergo CS with spinal anesthesia.
\end{abstract}

Key Words: postpartum hemorrhage, cesarean section, general anesthesia, spinal anesthesia, epidural anesthesia.

\section{INTRODUCTION}

Postpartum hemorrhage (PPH) is
considered the leading cause of pregnancy related deaths worldwide ${ }^{(\mathbf{1})}$, with an estimated 140,000 women dying annually from this complication ${ }^{(2)}$, equating to 1 every 4 minutes $^{(\mathbf{3})}$.

Rates of PPH likely vary widely depending on practice patterns and both provider and patient characteristics. For instance, cesarean rates, which vary widely across regions, are likely to impact PPH rates. Traditionally, PPH has been defined as blood loss in excess of $500 \mathrm{ml}$ after a vaginal birth and over $1000 \mathrm{ml}$ after a cesarean delivery. However, studies using chromate-tagged red blood cells have found that the average blood loss at vaginal delivery typically exceeds 500 $\mathrm{ml}^{(4)}$.

Primary postpartum hemorrhage (PPH) is the most common form of major obstetric hemorrhage. The traditional definition of primary PPH is the loss of $500 \mathrm{ml}$ or more of blood from the genital tract within 24 hours of the birth of a baby ${ }^{(5)}$.

Blood loss of more than $40 \%$ of total blood volume (approx $2800 \mathrm{ml}$ ) is generally regarded as 'life threatening'. It seems appropriate that PPH protocols should be instituted at an estimated blood loss well below this figure, as the aim of management is to prevent hemorrhage escalating to the point where it is life-threatening ${ }^{(6)}$.

If anaesthesia is required for examination and/or surgical intervention and haemodynamic stability is compromised, general anaesthesia is usually indicated. Haemodynamic compromise and coagulopathy should be addressed prior to surgery whenever possible although surgical control may at times be required to enable effective resuscitation. Regional anaesthesia may be contra-indicated due to maternal coagulopathy and risk of neuraxial haeamatoma as well as haemodynamic compromise. In addition, surgery may be lengthy with the potential for further patient 
deterioration. Rapid sequence induction is indicated, preferably following antacid prophylaxis (e.g. sodium citrate and ranitidine $)^{(7)}$.

The aim of the study is to detect risk of developing postpartum hemorrhage through the following objectives:

1- To assess frequency of post partum hemorrhage in general anaesthesia.

2- To assess frequency of post partum hemorrhage in spinal/ epidural anaesthesia.

3- To compare the risk of post partum hemorrhage $(\mathrm{PPH})$ for patients who will undergo cesarean delivery (Cs) with general versus spinal/epidural anaesthesia.

\section{PATIENTS AND METHODS}

This is retrospective study of all patients who have undergone caesarean section in Emergency Unit of Obstetrics and Gynecology Department, Faculty of Medicine, Zagazig University Hospitals in the period of one year from January 2012 till January 2013 (record-based study).

We collected data from files of operative sheet of the patients to detect number of patients who developed postpartum hemorrhage. We took 3937 cases who underwent CS 1664 cases received general anaesthesia , 2273 cases received spinal anaesthesia. 76cases of them developed postpartum hemorrhage, 59 cases received general anaesthesia and 17 cases received spinal anaesthesia.

All postpartum hemorrhagic patients were analyzed as regard:

1- Age.

2- Parity.

3- Type of anesthesia.

4- Operative time.

5- Occurrence of primary postpartum hemorrhage.

6- Blood transfusion.

7- complication.

\section{Exclusion criteria:}

- Contraindications to spinal anesthesia

- Preterm labor

- Cases with uterine fibroid
- Hypertension or cardiac diseases

- Cases with high risk for post partum hemorrhage as :-

- Placenta previa - placenta accrete - placental abruption

- Cases with prolonged labour - over distended utrus

Methods:

- Estimation of vaginal blood loss include :-

- Visual estimation, direct collection, venous blood sampling for determination of $\mathrm{HB}$ concentration.

- The total volume of crystalloid solutions infused during operation and duration of operation were determined.

\section{Statistical analysis:}

Data were entered checked and analyzed using Epi-Info version 6 and SPSS for Windows version 8 .

Data were summarized using: the arithmetic mean, the standard deviation, student $t$ test, chi-squared test.

For all above mentioned statistical tests done, the threshold of significance is fixed at $5 \%$ level (p-value).

The results was considered:

- Significant when the probability of error is less than $5 \%(\mathrm{p}<0.05)$.

- Non-significant when the probability of error is more than $5 \%(\mathrm{p}>0.05)$.

- Highly significant when the probability of error is less than $0.1 \%(\mathrm{p}<0.001)$.

The smaller the p-value obtained, the more significant are the results.

\section{RESULTS}

Table (1) shows that the age of all C.S cases ranged from 18 to 40 years with mean 23.97 years. Regarding parity $44.5 \%$ of cases were primigravida and $43.6 \%$ of them were multigravida.

Table (2) shows that only $1.9 \%$ of the studied group had post-partum $\mathrm{Hg}$

Table (3) shows that $42.3 \%$ of the studied group had general anesthesia and $57.7 \%$ of them had spinal anesthesia. Also $82.2 \%$ of the cases were previous caesarean section and $17.8 \%$ of them had indications of cesarean section. 
Table (4) shows that there was no statistical significance difference between general group and spinal group in age or parity.

Table (5) shows that there was statistical significance difference between general group and spinal group in number of cases who developed postpartum hemorrhage, as there is significnat high value in patietns who underwent general anesthesia.

Table (6) shows that there was no statistical significance difference between general group and spinal group as regard the indications of cesarean section.

Table (1): Demographic data of all C.S. cases:

\begin{tabular}{|c|c|c|}
\hline Variable & \multicolumn{2}{|c|}{$(n=3937)$} \\
\hline Age: & \multirow{3}{*}{\multicolumn{2}{|c|}{$\begin{array}{c}23.97 \pm 3.36 \\
18-40\end{array}$}} \\
\hline Mean $\pm S D$ & & \\
\hline Range & & \\
\hline Variable & No & $\%$ \\
\hline \multicolumn{3}{|l|}{ Parity: } \\
\hline$P G$ & 1751 & 44.5 \\
\hline$P 1$ & 1446 & 36.7 \\
\hline$P 2$ & 245 & 6.2 \\
\hline$P 3$ & 27 & 0.68 \\
\hline$P 4$ & 1 & 0.02 \\
\hline
\end{tabular}

SD: stander deviation

Table (2): Post-partum hemorrhage in all C.S. cases:

\begin{tabular}{lcc}
\hline \multirow{2}{*}{ Variable } & \multicolumn{2}{c}{$(\boldsymbol{n = 3 9 3 7 )}$} \\
\cline { 2 - 3 } & No & $\%$ \\
\hline Post-partum Hg: & & \\
No & 3861 & 98.1 \\
Yes & 76 & 1.9 \\
\hline
\end{tabular}

Table (3): Type of used anesthesia in all C.S. cases:

\begin{tabular}{lcc}
\hline \multirow{2}{*}{ Variable } & \multicolumn{2}{c}{$(\boldsymbol{n = 3 9 3 7 )}$} \\
\cline { 2 - 3 } & No & $\%$ \\
\hline Type of anesthesia: & & \\
General & 1664 & 42.3 \\
Spinal & 2273 & 57.7 \\
\hline Repeat CS & 3235 & 82.2 \\
Emergency CS & 702 & 17.8 \\
\hline
\end{tabular}


Table (4): Comparison between general anesthesia and spinal anesthesia group in demographic data:

\begin{tabular}{|c|c|c|c|c|c|c|}
\hline Variable & \multicolumn{2}{|c|}{$\begin{array}{c}\text { General } \\
(n=1664)\end{array}$} & \multicolumn{2}{|c|}{$\begin{array}{c}\text { Spinal } \\
(n=2273)\end{array}$} & $\mathbf{t}$ & $\mathbf{p}$ \\
\hline $\begin{array}{l}\text { Age: } \\
\text { Mean } \pm S D \\
\text { Range }\end{array}$ & \multicolumn{2}{|c|}{$\begin{array}{c}24.05 \pm 3.30 \\
18-40 \\
\end{array}$} & \multicolumn{2}{|c|}{$\begin{array}{c}23.91 \pm 3.40 \\
18-39 \\
\end{array}$} & \multirow{2}{*}{$\frac{1.27}{\chi^{2}}$} & \multirow{2}{*}{$\begin{array}{c}0.20 \\
\text { N.S } \\
\mathbf{P}\end{array}$} \\
\hline Variable & No & $\%$ & No & $\%$ & & \\
\hline $\begin{array}{l}\text { Parity: } \\
P G \\
P 1 \\
P 2 \\
P 3 \\
P 4\end{array}$ & $\begin{array}{c}727 \\
630 \\
99 \\
12 \\
0\end{array}$ & $\begin{array}{c}43.7 \\
37.9 \\
5.9 \\
0.7 \\
0 \\
\end{array}$ & $\begin{array}{c}1024 \\
816 \\
146 \\
15 \\
1 \\
\end{array}$ & $\begin{array}{c}45.1 \\
35.9 \\
6.4 \\
0.69 \\
0.01\end{array}$ & 2.55 & $\begin{array}{l}0.77 \\
\text { N.S }\end{array}$ \\
\hline
\end{tabular}

SD: stander deviation

Table (5): Rate of occurrence of postpartum hemorrhage in both studied groups (general and spinal groups):

\begin{tabular}{|c|c|c|c|c|c|c|}
\hline \multirow[t]{2}{*}{ Variable } & \multicolumn{2}{|c|}{$\begin{array}{c}\text { General } \\
(n=1664)\end{array}$} & \multicolumn{2}{|c|}{$\begin{array}{c}\text { Spinal } \\
(\mathrm{n}=2273)\end{array}$} & \multirow[t]{2}{*}{$\chi^{2}$} & \multirow[t]{2}{*}{$\mathbf{P}$} \\
\hline & No & $\%$ & No & $\%$ & & \\
\hline \multicolumn{7}{|l|}{ Post-partum Hg: } \\
\hline No & 1605 & 96.5 & 2256 & 99.3 & 39.72 & $<0.001 * *$ \\
\hline Yes & 59 & 3.5 & 17 & 0.7 & & \\
\hline
\end{tabular}

Table (6): Comparison between general anesthesia and spinal anesthesia group as regard the indications of $C S$

\begin{tabular}{lccccccc}
\hline \multirow{2}{*}{ Variable } & \multicolumn{2}{c}{$\begin{array}{c}\text { General } \\
(\mathbf{n = 1 6 6 4 )}\end{array}$} & \multicolumn{2}{c}{$\begin{array}{c}\text { Spinal } \\
(\mathbf{n = 2 2 7 3})\end{array}$} & \multirow{2}{*}{$\chi^{\mathbf{2}}$} & P \\
\cline { 2 - 5 } & No & \% & No & \% & & \\
\hline Repeat $C S$ & 1365 & 82 & 1870 & 82.3 & 0.04 & 0.85 \\
Emergency $C S$ & 299 & 18 & 403 & 17.7 & & N.S \\
\hline
\end{tabular}

\section{DISCUSSION}

Postpartum hemorrhage $(\mathrm{PPH})$ remains to be the most common cause of maternal mortality and is responsible for $25 \%$ of the maternal deaths worldwide. Although the absolute risk of maternal death is much lower, a recent increase of $\mathrm{PPH}$ and related maternal adverse outcomes has been noted in highincome countries as well. Generally, PPH requires early recognition of its cause, immediate control of the bleeding source by medical, mechanical, invasive non-surgical and surgical procedures, rapid stabilization of the mother's condition, and a multidisciplinary $\operatorname{approach}^{(8)}$.

Some medical agents and various surgical methods are used in the prevention or reduction of these hemorrhages ${ }^{(9)}$.

Anesthetic management of CS, which includes general anesthesia and spinal/epidural anesthesia, rarely has been studied for the risks that are associated with 
PPH and has been based on only a limited number of cases from single hospital datasets $^{(\mathbf{1 0})}$.

The aim of our study was to compare the risk of post partum hemorrhage (PPH) for patients who will undergo cesarean delivery (Cs) with general versus spinal/epidural anaesthesia.

This study was conducted on 3937 patients complicated by postpartum hemorrhage after cesarean section with history of type of anaesthesia used; general or spinal or epidural.

The patients were subjected to measurement of heart rates and blood pressures, assessment of uterine contractility, recording hemoglobin concentration and determination of the total volume of crystalloid solutions infused during operation and duration of operation.

Our results showed that there was no statistical significant difference between patients who received general anesthesia and patients who received spinal anesthesia in age, parity and as regard the indication of cesarean section but There was statistical significant difference between patients who received general anesthesia and patients who received spinal anesthesia in number of cases having postpartum hemorrhage.

Our study was in agreement with Magann et al. ${ }^{(10)}$ who stated that general anesthesia was associated with higher odds of PPH than spinal/epidural anesthesia, with adjusted Ors that ranged from 2.79 to 4.81 and Al-Zirqi et al. ${ }^{\text {(11) }}$ who reported that general anesthesia carried significantly higher odds of PPH than spinal/epidural anesthesia, with an estimated adjusted OR of 2.94.

Chang et al. ${ }^{(12)}$ compared the risk of PPH after CS for those who receive general versus spinal/epidural anesthesia. They concluded that the odds that women will experience cesarean $\mathrm{PPH}$ with general anesthesia are approximately 8.15 times higher than for women who undergo CS with epidural anesthesia.

The plausible mechanisms by which general anesthesia carries a higher risk of PPH than spinal/epidural anesthesia might be classified into 2 categories. First, many drugs that are used for general anesthesia have been demonstrated to exert a suppressive effect on uterine contraction. Intravenous general anesthetics (which include propofol, midazolam, and ketamine), volatile anesthetics (which include halothane, enflurane, isoflurane, sevoflurane, and desflurane), and opioids (which include alfentanil, meperidine, and remifentanil) have all been shown to suppress the contraction of animal and/or human uterine muscles. On the other hand, the myometrial activity of local anesthetics that are used in spinal/epidural anesthesia (which include prilocaine, ultracaine, procaine, lidocaine, bupivacaine, and ropivacaine) has been demonstrated to be non-monotonic ${ }^{(\mathbf{1 3})}$.

Spinal/epidural anesthesia has been contraindicated relatively for women who are at risk of major hemorrhage because of concerns about hemodynamic instability and the need to resuscitate an awake patient. General anesthesia with a secured airway is still recommended to facilitate preparation for rapid massive transfusion and potential complications, which include hysterectomy ${ }^{(\mathbf{1 4})}$.

\section{CONCLUSION}

The choice of anesthetic techniques could be influenced by the presence of or concern about bleeding. We concluded that women who received general anaesthesia were at higher risk of post partum hemorrhage compared with women who received epidural, spinal anaesthesia.

We recommend to use spinal or epidural anaesthesia for those having high risk factors for post partum hemorrhage, this is better than using general anaesthesia for those cases.

We recommend to make carful follow up for risk cases recieving general anaesthesia to protect them from cesarean post partum hemorrhage

\section{REFERENCES}

1- World Health Organization. Maternal mortality in 2000; estimates developed by WHO, UNICEF, and UNFPA. Geneva: WHO; 2004.

2- AbouZahr C. Global burden of maternal death and disability. Br Med Bull. 2003; 67:1-11.

3- ACOG Practice Bulletin. Clinical management guidelines for obstetriciangynecologists number 76, October 2006: postpartum hemorrhage. Obstet Gynecol. 2006;108:1039-1047. 
4- Oyelese $\mathbf{Y}$ and Ananth CV. Postpartum Hemorrhage: Epidemiology, Risk Factors, and Causes. Clin obstet gynecol 2010; 53 (1): 147156

5- Mousa HA and Alfirevic Z. Treatment for primary postpartum hemorrhage. Cochrane Database Syst Rev 2007; 1:CD003249.

6- Toledo P, McCarthy RJ and Hewlett BJ The accuracy of blood loss estimation after simulated vaginal delivery. Anesth Analg. 2007; 105: 1736-1740

7- Walfish M, Neuman A, Wlody D. Maternal Haemorrhage. British Journal of Anaesthesia 2009; 103 (Suppl 1): i47-56

8- Rath W, Hackethal A, Bohlmann MK. Second-line treatment of postpartum haemorrhage. Arch Gynecol Obstet 2012; 286(3):549-56112 .

9- Gungorduk K, Yıldırım G. Efficacy of Intravenous Tranexamic acid in reducing blood loss after elective caesarean section: a prospective, randomized, double-blind placebo-Controlled Study. Am J Perinatol 2011; 28(3):233-240.

10- Magann EF, Evans $S$, Hutchinson M, et al. Postpartum hemorrhage after cesarean delivery: An analysis of risk factors. South Med J 2005; 98: 681-5.

11- Al-Zirqi I, Vangen S, Forsen $L$, et al. Prevalence and risk factors of severe obstetric haemorrhage. BJOG 2008; 115: 1265-72.

12- Chang C, Wang I, Chen $Y$, et al. Anesthetic management as a risk factor for postpartum hemorrhage after cesarean deliveries. Am J Obstet Gynecol 2011; 205: 462-7.

13- Thind AS and Tumer RJ. In vitro effects of propofol on gravid human myometrium. Anaesth Intensive Care 2008; 36: 802-6.

14- Gallos G, Rectai I and Smiley RM. The role of the anesthesiologist in management of obstetric hemorrhage. Semin Perinatol 2009; 33: 116-2. 